\title{
Study on the Gelation of Foamed Gel for Preventing the Spontaneous Combustion of Coal
}

\author{
Leilin Zhang ${ }^{1}$ and Botao Qin ${ }^{2}$ \\ ${ }^{1}$ School of Mining and Safety Engineering, Anhui University of Science \& Technology, Huainan 232001, China \\ ${ }^{2}$ School of Safety Engineering, China University of Mining \& Technology, Xuzhou 221116, China \\ Correspondence should be addressed to Leilin Zhang; leilinzhang@126.com
}

Received 28 May 2014; Revised 15 June 2014; Accepted 16 June 2014; Published 26 June 2014

Academic Editor: Tifeng Jiao

Copyright (c) 2014 L. Zhang and B. Qin. This is an open access article distributed under the Creative Commons Attribution License, which permits unrestricted use, distribution, and reproduction in any medium, provided the original work is properly cited.

\begin{abstract}
According to the existing deficiencies in fire prevention technology, a new technique named foamed gel is developed to prevent coal mine fire efficiently. Foamed gel, formed by adding the type $\mathrm{F} 3 \mathrm{foam}$ agent, polymer $\mathrm{H}$, and $\mathrm{AL}$ into water, introducing nitrogen and stirring physically and mechanically, is a complex multicomponent foam system. The effects of the mass fraction and mixed ratios of polymer $\mathrm{H}$ and polymer AL blends on gelation were comprehensively studied. The results show that the optimum performance can be got when the mass fraction of blends was $0.6 \%$ and the mixed ratio was $5: 5$. In addition, the interaction between molecules of these polymer blends was also investigated with the help of atomic force microscope. It can be found that the polymers $\mathrm{H}$ and $\mathrm{AL}$, through having crosslinking reaction with each other, formed three-dimensional network structures, which can not only increase the nodes of the foamed gel system but also enhance the structures.
\end{abstract}

\section{Introduction}

Spontaneous combustion of coal in goaf is one of the main natural disasters in coal mine production $[1,2]$. In recent years, in China, technology of fully mechanized sublevel caving mining is extensively used; besides, gas extraction technique has been widely promoted in the gas treatment. The significant improvement of production efficiency and the dramatical reduction of gas emission have caused leakage serious in goaf, making the coal spontaneous combustion occur frequently [3-5]. For the past few years, the number of the working face of China key state-owned coal mines closed has been over one hundred because of spontaneous fire and the freezing coals caused by the work of closing were more than ten million tons. Closing working face often makes tens of millions of equipment of fully mechanized face and fully mechanized sublevel caving face closed in spontaneous fire area, a great deal of coal frozen and reasonable sequence of deploitation dispose and mining preparation broken, which bring a large economic loss and major hidden danger to mine. In order to prevent the spontaneous combustion of coal, the techniques of grouting, nitrogen, inhibitor, gel, foam, and so on are adopted to prevent coal spontaneous combustion since 1950s [6-8]. Although those techniques have supplied an important guarantee for the mine safety production, due to the extremely complex condition of coal mine, all of them can not completely meet the need of fire prevention and extinguishing. When grouting, slurry can only flow to the low-lying areas and can not cover the coal in higher places in goaf. While injecting nitrogen, it is easy for gas to spread with air but it is difficult to stay in the infuse area and thereby the effect of fire extinguishing and cooling is not ideal. If injecting inhibitor, which is hard to evenly disperse on the coal and has corrosive action, threatening both equipment and the health of workers. When injecting polymer gelatin, the small flow is difficult to be applied to put out the fire in large areas of goaf. If injecting foam, which can not realize curing and whose normally stability is $8 \sim 12 \mathrm{~h}$. Therefore, the work of fire prevention and extinguishing in coal mine is still an arduous task for scholars at home and abroad [9].

In order to overcome the deficiencies in conventional fire prevention and extinguishing technology, foamed gel, for the first time, is developed to prevent the spontaneous combustion of coal. Foamed gel, a complex mixed system, is 
formed by adding polymers and foaming agent into water and stirring physically and mechanically under the function of nitrogen. After a while, different polymers take crosslinking reaction in foam films and form three-dimensional network structures, which constitute the rigid backbone of foamed gel. The foamed gel not only has the properties of gel but also has the characteristics of foam; at the same time, it can also overcome the shortages of both and thus significantly improve the effect of fire prevention and extinguishing. At present, foamed gel, preliminarily investigated in petroleum exploitation and related industries, is mostly used as plugging agent and profile control so as to increase the mining rate of petroleum. Researchers at home and abroad have made many great contributions in this field. Fogler research team of Michigan College carried out a deep experiment on foamed gel's infiltration, flow direction, mechanical strength, and so on in the 1990s [10-14]. Zhiguo et al. studied the selective water plugging agent of foamed gel [15]. Qibin et al. explored the stability of foamed gel [16]. Although the foamed gel has a lot of advantages and good application result, the study on the effect of fluidity and formation mechanism is far from satisfactory, limiting its application. Furthermore, foaming multiple of foamed gel adopted in petroleum exploitation is small and gelation time is long, while those of foamed gel used in coal mine for fire prevention and extinguishing are high and controllable (generally 10 20 min), more difficult to investigate, and with more complex influencing factors.

This paper takes type F3 foaming agent, polymer $\mathrm{H}$, and $\mathrm{AL}$ as the basic material, pays more attention to the effect of mass concentration and mixed ratio of polymer blends on gelation property, and analyzes the mechanism of crosslinking action between two polymers with the help of atomic force microscope, which provide a foundation for this system as a new type of material for preventing spontaneous combustion of coal.

\section{Experimental Preparation}

2.1. Experimental Material. Polymers $\mathrm{H}$ and AL are produced by Henan Kuangyuan Chemical Product Co., Ltd. The polymer $\mathrm{H}$ is an anionic polysaccharide produced by fermentation from Xanthomonas campestris. The polymer AL is a kind of galactomannan polysaccharide obtained from Cyamopsis tetragonoloba seeds. Both of them dissolve readily in water at room temperature. They are polysaccharides, which are particularly used for the food industry. The main role of these is to serve as a thickening agent and texture modifiers for food products. The unique characteristic of them is that not only do they owe significant viscosity values at lower concentrations in aqueous solutions but also they can exhibit excellent crosslinking when they are mixed.

Type F3 foaming agent was made by us; the concentration of active matter was 30 32\%.

2.2. Experimental Equipment. Philips type HR2006 agitator, atomic force microscope, and type NDJ-5s digital viscometer

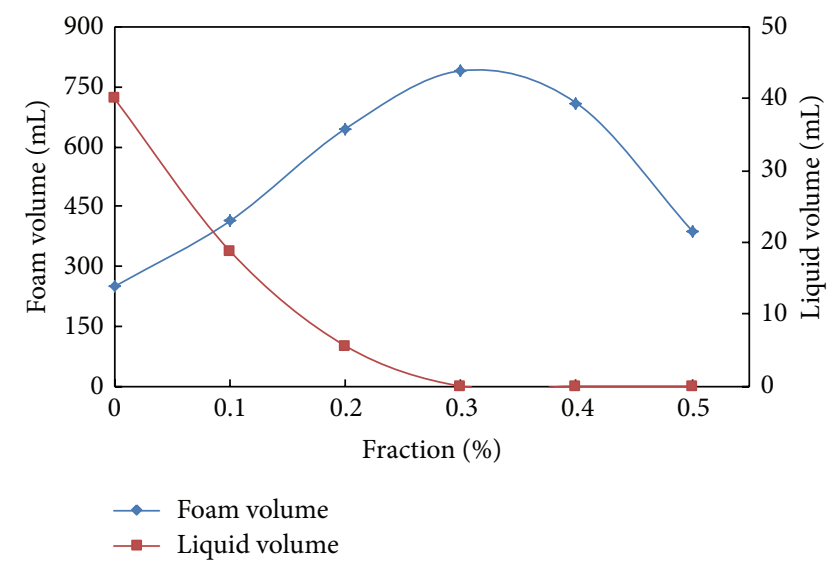

FIGURE 1: Gelation against the mass fraction of polymer blends.

are used. The viscometer is divided into four crosspieces: 4.2 , $8.5,22.2$, and $42.4 / \mathrm{s}$, respectively.

\subsection{Experimental Methods}

(1) Put polymers $\mathrm{H}$ and AL blends into a suitable amount of water, then add certain type F3 foaming agent, and finally form the base fluid of foamed gel.

(2) Take $100 \mathrm{~mL}$ of the base fluid into agitator, foam by means of stirring physically and mechanically (for $5 \mathrm{~min}$ ), measure the foam volume and liquid dropout volume through its own measuring device, and use viscosimeter to test the viscosity of foamed gel.

\section{Results and Analysis}

3.1. Effect of Mass Fraction of Polymer Blends on Gelation of Foamed Gel. At room temperature, mass fraction of type F3 foaming agent is fixed at $0.4 \%$, and mixed ratio of polymers $\mathrm{H}$ and $\mathrm{AL}$ is $1: 1$, investigating the effects of mass fraction of the polymer blends on the foam volume and liquid dropout volume, which is shown in Figure 1.

As shown in Figure 1, with the increase of the mass fraction of polymer blends, the foam volume first increased and then decreased, but the liquid dropout volume rapidly decreased to zero. This is because the optimal polymer $\mathrm{H}$ has the high surface activity, which can increase the intersolubility between components and control cell size and uniformity, increasing the foam volume. However, the viscosity of the solution was low when the mass fraction of polymer was small, and crosslinking points in the polymers were less and three-dimensional network structures can not be formed; thus a small amount of liquid can be seen in the foam bottom after standing for some time. With the increasing of mass fraction of polymer blends, polymers $\mathrm{H}$ and $\mathrm{AL}$ firstly fully diffuse in foam films and then have crosslinking reaction with each other to form three-dimensional network structures, constituting the rigid backbone of foam and greatly enhancing the stability of foam [17]. Furthermore, the molecular chains of the polymers contain a lot of $-\mathrm{OH}$, 


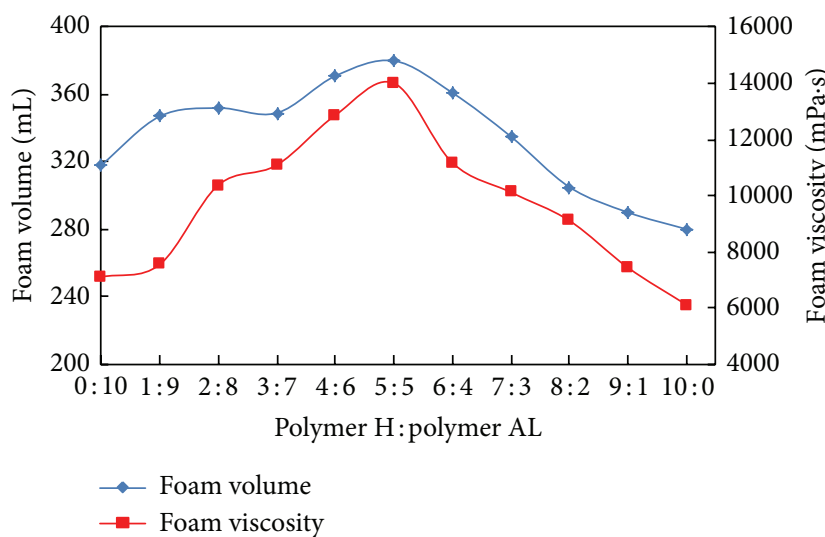

FIgURE 2: The influence of mixed ratio on gelation of foamed gel.

which can interact with the water molecules by hydrogen bonds. Consequently, water is absorbed in three-dimensional network structures, which can maintain the stability of foam. If the mass fraction of polymer blends exceeds $0.6 \%$, the viscosity of the system rapidly increases, the penetration of gas is poor, and foam volume decreases gradually [18]. Therefore, when the mass fraction of polymer blends is $0.6 \%$, the best foaming effect of polymer solution can be got and the gelation properties of foamed gel produced are the best.

3.2. Effect of Mixed Ratio of Polymer Blends on Gelation of Foamed Gel. The mass fraction of type F3 foaming agent is fixed at $0.4 \%$, the total mass fraction of polymer blends is $0.6 \%$, and the polymers $\mathrm{H}$ and $\mathrm{AL}$ are mixed at different compound proportions so as to form foamed gel, respectively. The effects of mixed ratios on foam volume and foam viscosity are shown in Figure 2.

From Figure 2, it can be seen that, with the increase of compound ratio, both foaming multiple and foam viscosity first rise and then decline. When the compound proportion of polymers $\mathrm{H}$ and $\mathrm{AL}$ is $5: 5$, foaming multiple and foam viscosity are the maximum. If the ratio continues to change, foaming multiple and foam viscosity begin to fall, which means that there exists a best compound ratio of the blends, and by this time, their crosslinking reaction with each other is maximum.

The reason for this phenomenon is that when polymers $\mathrm{H}$ and $\mathrm{AL}$ mixed in the solution, they can fully react with each other and form three-dimensional network structures, making the viscosity of foamed gel increase. Whereas if the mass fraction of polymer $\mathrm{H}$ is less, the polymer $\mathrm{AL}$ will be excessive, unexpectedly its dense galactose will hinder the interaction with polymer $\mathrm{H}$, causing the viscosity of the system to descend and not to form foamed gel with satisfactory stability and good appearance. With the rise of polymer $\mathrm{H}$, foaming property and stability of the solution increase gradually. However, when mass fraction of polymer $\mathrm{H}$ is more than $50 \%$, the polymer AL relatively reduces and the crosslinking points decrease, unhelpful to form gel [19-21]. Foam property becomes worse and stratification

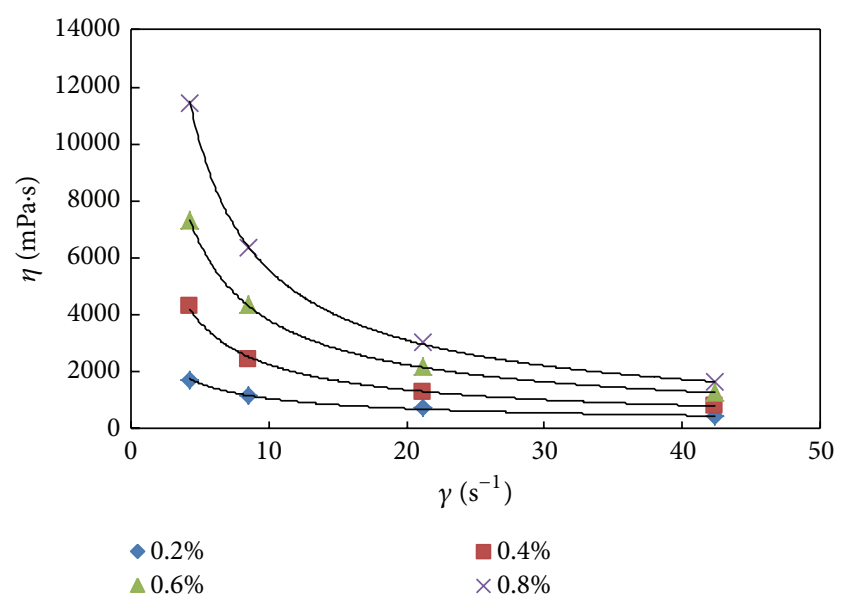

FIGURE 3: Relationship between apparent viscosity and shear rate of foamed gel.

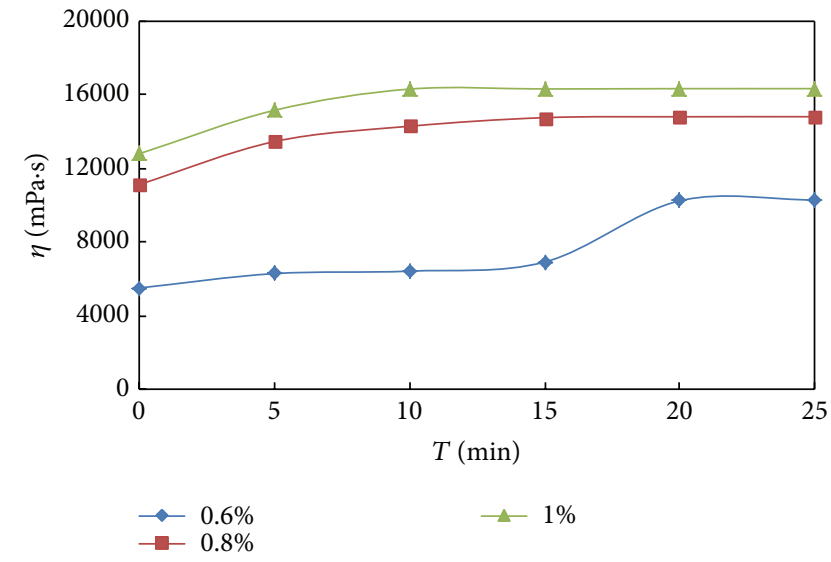

FIGURE 4: Relationship between mass fraction of blends and gelation time of foamed gel.

phenomenon can be seen after standing for a while. Consequently, when the mixed ratio of the blend is $5: 5$, foam property and gelation effect are the best.

3.3. Characteristics of Gelation of Foamed Gel. According to the research conducted above, the foamed gel is formed when the mass fraction of type F3 foaming agent is fixed at $0.4 \%$ and the mass fractions of polymers $\mathrm{H}$ and $\mathrm{AL}$ are both $0.3 \%$. Viscometer is adopted to measure the apparent viscosity so as to discuss the relationship between gelation property and shear rate, as shown in Figure 3.

According to the research conducted above, the concentration of type F3 foaming agent is fixed at $0.4 \%$, and the mass ratio of polymers $\mathrm{H}$ and $\mathrm{AL}$ is $1: 1$. Then change the concentration of mixture so as to form the foamed gel samples at different concentrations and use viscometer to measure the apparent viscosity at different shear rate, as shown in Figure 3.

It can be seen from Figure 3 that the apparent viscosity of foamed gel at various concentrations of the mixture formed 


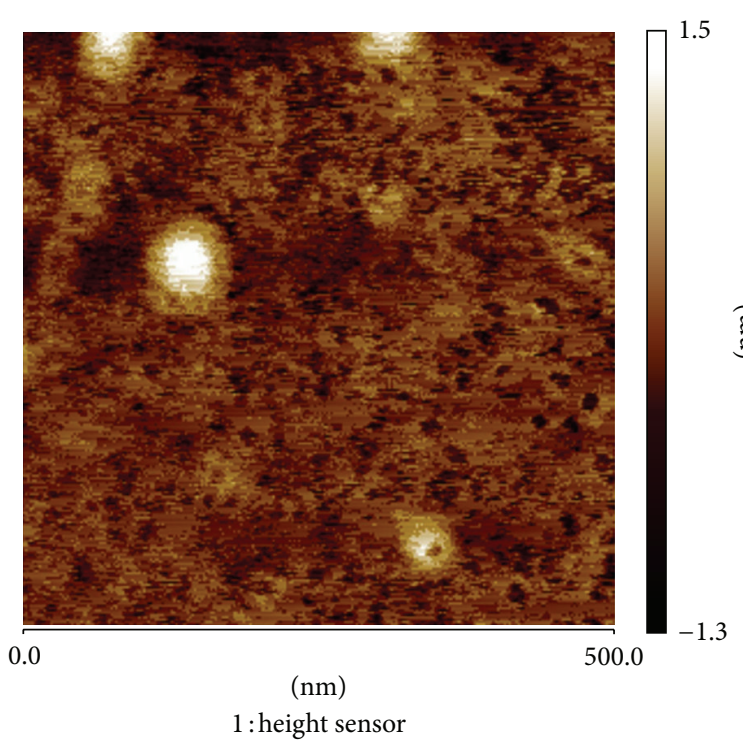

(a)

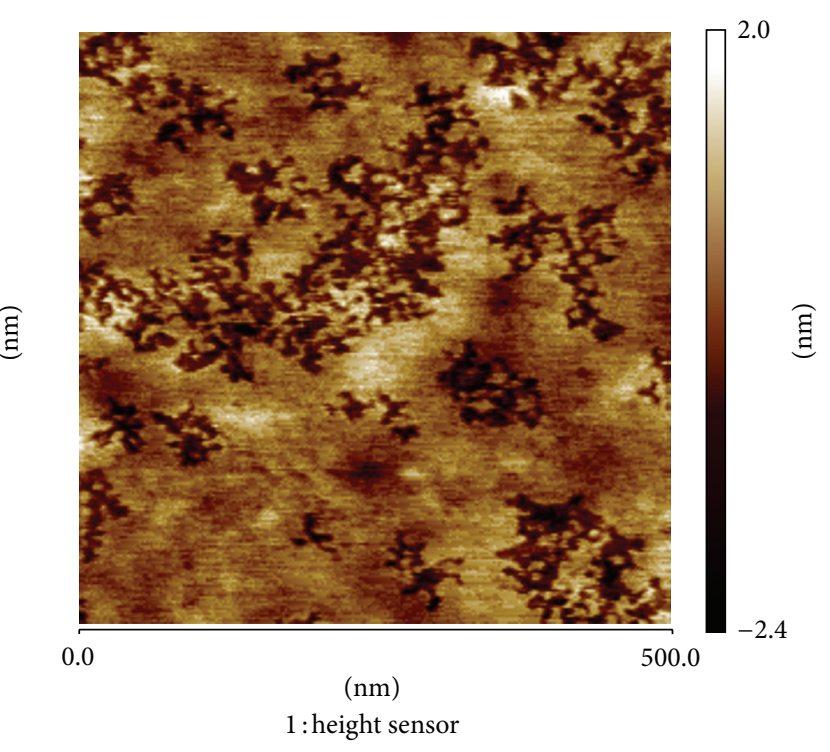

(b)

FIgURE 5: AFM images of foamed gel samples in the scanning range of $500 \mathrm{~nm}$. (a) Polymer H; (b) polymers $\mathrm{H}$ and AL blends.

by polymers $\mathrm{H}$ and $\mathrm{AL}$ drops rapidly with the shear rate increasing, and the higher the concentration is, the more obviously apparent the viscosity decrease is. This law fits the fluid character of shear thinning. In static foamed gel, the arrangement of molecular chains in polymers is ruleless. And those molecular chains entangle with each other to form three-dimensional network structures, producing viscous resistance to flow [22]. Therefore, when the shear rate is low, the apparent viscosity of foamed gel is high. With the increase of shear rate, the shear effect subjected to three-dimensional network structures rises, and the molecules curved and entangled was open. Molecules nodes reduce, thus apparent viscosity decreases. When the shear rate reaches a certain value, the apparent viscosity is stable [23, 24]. Hence, under the function of shear rate, polymers $\mathrm{H}$ and $\mathrm{AL}$ can not have crosslinking reaction with each other in foam films, which can meet the property of large range flow and diffusion of foamed gel in goaf.

3.4. Gelation Time. The formation process of foamed gel is that, after the system foams, polymers $\mathrm{H}$ and $\mathrm{AL}$ contained in foam films react with each other and form foamed gel. If the time of crosslinking reaction between polymers is too early, the viscosity of solution will be too high and hard to form foam. Even if foamed gel is formed, the large viscosity makes it difficult to flow; the limited overage can not meet the need of fire prevention and extinguishing. Foam belongs to unstable system of thermodynamics; if the time of crosslinking reaction between polymers is too late and even exceeds its stable time, it will break and dehydrate. At this time, even if crosslinking reaction has been taken place, the foamed gel can not be formed. Therefore, the best gelation time is after the solution foaming and before its breaking. Considering that the pipe transport is used in coal mines, the time is controlled between 10 20 min. After the blends

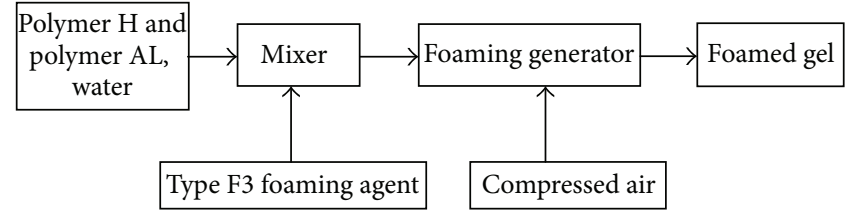

FIGURE 6: The flowchart for preparation of foamed gel.

mixed, the viscosity begins to increase. After some time, the viscosity is essentially constant and forms stable foamed gel. Polymers $\mathrm{H}$ and $\mathrm{AL}$ are chosen to investigate how the gelation time changes at different mass concentrations of the polymer blends.

The mass fraction of type $\mathrm{F} 3$ foaming agent is fixed at $0.4 \%$. The compound proportion of polymers $\mathrm{H}$ and $\mathrm{AL}$ is $1: 1$; then prepare the polymer blends with the mass fraction of $0.6 \%, 0.8 \%$, and $1 \%$, respectively. To study on the effect of various mass fractions on gelation time, the results are shown as follows.

From Figure 4, it can be found that, when the mass fraction of blends was $0.6 \%$, the gelation time was $20 \mathrm{~min}$. When the mass concentration of the blends increased to $1 \%$, the gelation time decreased to $10 \mathrm{~min}$. This is because the rise of mass fraction leads to shortening of the distance and increasing of the collision between molecules. The crosslinking reaction between polymers $\mathrm{H}$ and AL becomes stronger, which makes great contributions to forming threedimensional network structures with strong continuity [25]. Therefore, the gelling rate of foamed gel increased with the rise of the mass fraction of polymer blends. Moreover, the highest gelation viscosity of the system increased with the rising of the mass concentration. Nevertheless, if the mass concentration is too high, the reaction rate among polymers increases and gelling rate of the system speeds up, not easy to 


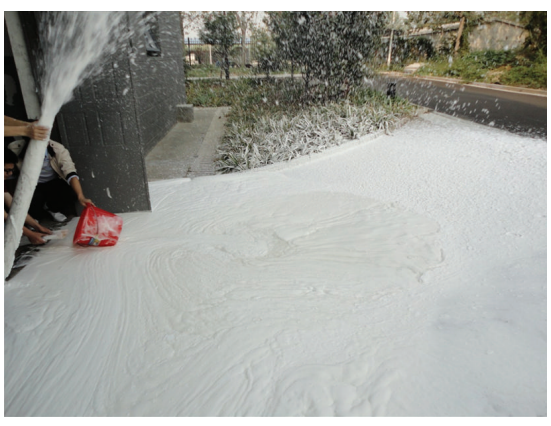

(a)

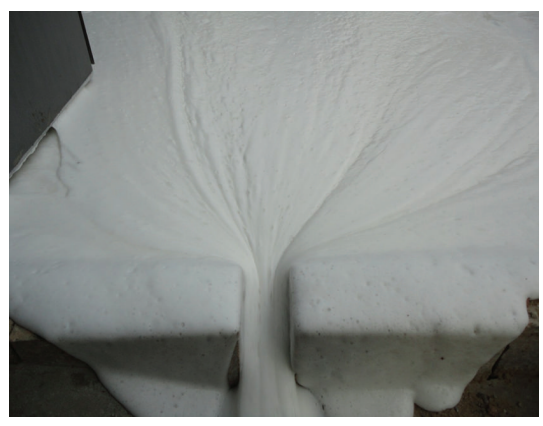

(b)

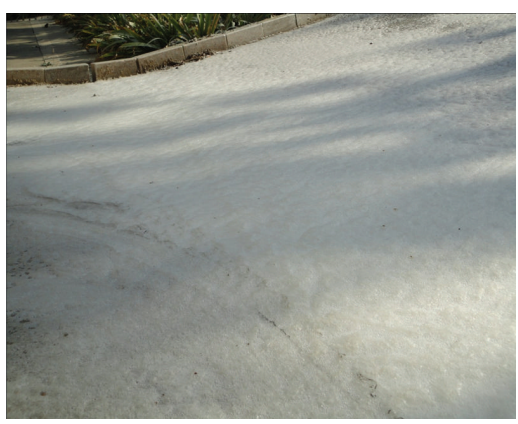

(c)

FIGURE 7: The foamed gel prepared in lab. (a) Foaming, (b) fluidity, and (c) film forming ability.

control the gelation time. Furthermore, the rise of the mass fraction of polymer increases the viscosity of the solution, reducing foaming ability.

3.5. Microstructure Analysis. Prepare the mass fraction of $0.3 \%$ of polymer $\mathrm{H}$ and the mass fraction of $0.3 \%$ of both polymers $\mathrm{H}$ and $\mathrm{AL}$, respectively; take $10 \mu \mathrm{L}$ of the two solution samples on mica sheet, and make it spread as possible as you can, heating slightly into membrane. Use AFM to observe the microstructure under the scanning range of $500 \mathrm{~nm}$, as shown in Figure 5.

We can see from Figure 5 that the microstructure map of polymer $\mathrm{H}$ without polymer AL is chaotic, granularly distributed in the solution, and thus unable to form threedimensional network structures, as shown in Figure 5(a). With the adding of polymer AL, filled in the molecules of polymer $\mathrm{H}$, making the scattered polymer $\mathrm{H}$ form a uniform continuous phase and thereby form three-dimensional network structures, as shown in Figure 5(b). This is because when polymer $\mathrm{H}$ is dispersed into water, it first becomes pieces of random line structures. Then the random molecular chains will coalesce together to the double helix rigid structures similar to the rod by hydrogen bond between the side chain and main chain of polymer $\mathrm{H}$. The rodlike structures, with the help of $\mathrm{Na}^{+}, \mathrm{K}^{+}$, and $\mathrm{Ca}^{2+}$ ionized by polymer $\mathrm{H}$ itself, make the double helix structures decentralized in the solution connected together to the helical mesh polymer or double helix cluster by chains of $-\mathrm{COO}-\mathrm{Na}-\mathrm{H}_{2} \mathrm{O}-\mathrm{Na}-\mathrm{COO}-$, $-\mathrm{COO}-\mathrm{K}-\mathrm{H}_{2} \mathrm{O}-\mathrm{K}-\mathrm{COO}-$, and $-\mathrm{COO}-\mathrm{Ca}-\mathrm{COO}-[17,26]$. If polymer $\mathrm{AL}$ is not added, polymer and cluster can only be uniformly dispersed into the solution and can not form three-dimensional network structures. After adding polymer $\mathrm{AL},-\mathrm{CH}_{2} \mathrm{OH}$ in polymer or cluster and the $-\mathrm{CH}_{2} \mathrm{OH}$ in main chain of polymer $\mathrm{AL}$ contact and fully collide, forming three-dimensional network structures in the form of $-\mathrm{CH}_{2}-\mathrm{O}-\mathrm{CH}_{2}-$ and making the scattered polymer and cluster form a uniform continuous phase [27-29]. Consequently, polymer AL and polymer $\mathrm{H}$ can react with each other in foam films to form foamed gel and keep the stability of foam.

\section{Preparation and Effect}

In order to investigate the foaming effect of foamed gel, compressed air replacing nitrogen is used, and foaming device of foamed gel has been constructed to conduct a simulation test. Firstly, directly mix and stir polymer H, polymer AL, and water based on the fixed proportion to form the solution of blends. Then, put the blends solution into grouting pipes through consistency pump and take type F3 foaming agent into grouting pipes by fixed displacement pump. After fully mixed in the flow mixer, solution of polymers and foaming agent flow to the foaming generator. Then compressed air is introduced. Finally the air interacts with the blends solution with type F3 foaming agent and forms foamed gel. The process of preparing foamed gel is shown in Figure 6.

According to the experimental parameters above, the mass fraction of $0.4 \%$ of type F3 foaming agent and the mass fraction of $0.3 \%$ of both polymer $\mathrm{H}$ and polymer $\mathrm{AL}$ are used to form foamed gel, as shown in Figure 7(a). And the foamed gel prepared has good fluidity, as shown in Figure 7(b). After one day, polymer $\mathrm{H}$ and polymer AL have crosslinking interaction with each other in foam films and obtain compacted thin films, as shown in Figure 7(c).

\section{Conclusions}

(1) Experimental study on the properties of foamed gel shows it has the characteristics of high foaming multiple, strong stability, good fluidity, adjustable gelation time, and so forth. So using the foamed gel can significantly improve the efficiency of preventing spontaneous combustion of coal.

(2) The mass fractions of polymers $\mathrm{H}$ and $\mathrm{AL}$ and the compound proportion of the blends greatly influence the performances of foamed gel. When the mass fraction of polymer $\mathrm{H}$ and polymer AL blends is $0.6 \%$ and the mixed ratio is $1: 1$, the properties of foamed gel formed for fire prevention and extinguishing are the best, and the foamed gel prepared has the maximum viscosity without affecting its fluidity. 
(3) Through the analysis of AFM, polymers $\mathrm{H}$ and $\mathrm{AL}$ have crosslinking reaction with each other and form three-dimensional network structures, increasing the nodes of the system and enhancing the structures. Moreover, foaming device of foamed gel is constructed in lab and foamed gel for fire prevention and extinguishing with optimum performance is prepared.

\section{Conflict of Interests}

The authors declare that there is no conflict of interests regarding the publication of this paper.

\section{Acknowledgment}

The authors deeply appreciate the financial support of this work by the National Natural Science Foundation of China (no. U1361213).

\section{References}

[1] W. Jo, H. Choi, S. Kim et al., "A comparison of spontaneous combustion susceptibility of coal according to its rank," Korean Journal of Chemical Engineering, vol. 30, no. 5, pp. 1034-1038, 2013.

[2] A. K. Singh, R. V. K. Singh, M. P. Singh, H. Chandra, and N. K. Shukla, "Mine fire gas indices and their application to Indian underground coal mine fires," International Journal of Coal Geology, vol. 69, no. 3, pp. 192-204, 2007.

[3] W. Deming, D. Guolan, Z. Xiaoxing, X. Haihui, and Q. Botao, "An experimental approach to selecting chemical inhibitors to retard the spontaneous combustion of coal," Fuel, vol. 117, part A, pp. 218-223, 2014.

[4] Z. Xie, Z. Yu, and J. Cai, "Prediction of coal spontaneous combustion in goaf based on the BP Neural network," Procedia Engineering, vol. 43, pp. 88-92, 2012.

[5] J. Xie, S. Xue, W. Cheng, and G. Wang, "Early detection of spontaneous combustion of coal in underground coal mines with development of an ethylene enriching system," International Journal of Coal Geology, vol. 85, no. 1, pp. 123-127, 2011.

[6] F. Zhou, W. Ren, D. Wang, T. Song, X. Li, and Y. Zhang, "Application of three-phase foam to fight an extraordinarily serious coal mine fire," International Journal of Coal Geology, vol. 67, no. 1-2, pp. 95-100, 2006.

[7] Y. Xu, D. Wang, L. Wang, X. Zhong, and T. Chu, "Experimental research on inhibition performances of the sand-suspended colloid for coal spontaneous combustion," Safety Science, vol. 50, no. 4, pp. 822-827, 2012.

[8] G. B. Stracher and T. P. Taylor, "Coal fires burning out of control around the world: thermodynamic recipe for environmental catastrophe," International Journal of Coal Geology, vol. 59, no. 1-2, pp. 7-17, 2004.

[9] X. Xuefu, W. Hongtu, and J. Deyi, “The summarization of the investigation on coal mine fire prevention and fire extinguishing techniques in China," Engineering Science, vol. 3, no. 12, pp. 2832, 2001.

[10] J. M. Matthew, "Permeability of foamed gel barriers used for physical control of subterranean fluid movement," Dissertatio n Abstract International, vol. 56, no. 1, p. 382, 1995.
[11] M. J. Miller, K. Khilar, and H. S. Fogler, "Aging of foamed gel used for subsurface permeability reduction," Journal of Colloid and Interface Science, vol. 175, no. 1, pp. 88-96, 1995.

[12] M. J. Miller and H. S. Fogler, "A mechanistic investigation of waterflood diversion using foamed gels," SPE Production \& Facilities, vol. 10, no. 1, pp. 62-69, 1995.

[13] M. J. Miller and H. S. Fogler, "Foamed gel barriers in porous media: breakdown and permeability evolution," AIChE Journal, vol. 41, no. 11, pp. 2487-2398, 1995.

[14] J. M . Matthew and H. S. Fogler, "A model to estimate the performance of foamed gel for conformance control," in SPE/DOE Improved Oil Recovery Symposium, vol. 9, pp. 461473, 1994.

[15] S. Zhiguo, Su. Guo, and D. Yujie, "Development and application of a selective foamed gel plugging agent," Drilling \& Production Technology, vol. 23, no. 1, pp. 70-71, 2000.

[16] C. Qibin, M. Baoqi, and N. Binghua, "Effects of several factors on the properties of a foamed gel," Journal of East China University of Science and Technology (Natural Science Edition), vol. 33, no. 1, pp. 71-75, 2007.

[17] C.-F. Mao, Y.-C. Zeng, and C.-H. Chen, "Enzyme-modified guar gum/xanthan gelation: an analysis based on cascade model," Food Hydrocolloids, vol. 27, no. 1, pp. 50-59, 2012.

[18] S. N. Tan, A. Jiang, J. J. Liau, S. R. Grano, and R. G. Horn, “The surface dilational viscosity of polypropylene glycol solutions and its influence on water flow and foam behavior," International Journal of Mineral Processing, vol. 93, no. 2, pp. 194-203, 2009.

[19] H. A. Khouryieh, T. J. Herald, F. Aramouni, and S. Alavi, "Intrinsic viscosity and viscoelastic properties of xanthan/guar mixtures in dilute solutions: effect of salt concentration on the polymer interactions," Food Research International, vol. 40, no. 7, pp. 883-893, 2007.

[20] H. A. Khouryieh, T. J. Herald, F. Aramouni, and S. Alavi, "Influence of mixing temperature on xanthan conformation and interaction of xanthan-guar gum in dilute aqueous solutions," Food Research International, vol. 39, no. 9, pp. 964-973, 2006.

[21] J. A. Casas and F. García-Ochoa, "Viscosity of solutions of xanthan/locust bean gum mixtures," Journal of the Science of Food and Agriculture, vol. 79, no. 1, pp. 25-31, 1999.

[22] X. Zhou, F. Chen, and Zhang B., "Studies on the rheological properties of oxidized waxy maize starch paste," Cereal and Feed Industry, no. 9, pp. 27-30, 2010.

[23] T. G. Matuda, S. Chevallier, P. de Alcântara Pessôa Filho, A. LeBail, and C. C. Tadini, "Impact of guar and xanthan gums on proofing and calorimetric parameters of frozen bread dough," Journal of Cereal Science, vol. 48, no. 3, pp. 741-746, 2008.

[24] B. Heyman, W. H. de Vos, F. Depypere, P. van der Meeren, and K. Dewettinck, "Gums tuning the rheological properties of modified maize starch pastes: differences between guar and xanthan," Food Hydrocolloids, vol. 39, pp. 85-94, 2014.

[25] M. Tako and S. Nakamura, "Synergistic interaction between xanthan and guar gum," Carbohydrate Research, vol. 138, no. 2, pp. 207-213, 1985.

[26] M. Chaisawang and M. Suphantharika, "Pasting and rheological properties of native and anionic tapioca starches as modified by guar gum and xanthan gum," Food Hydrocolloids, vol. 20, no. 5, pp. 641-649, 2006.

[27] K. P. Shatwell, I. W. Sutherland, S. B. Ross-Murphy, and I. C. M. Dea, "Influence of the acetyl substituent on the interaction of xanthan with plant polysaccharides-II. Xanthan-guar gum systems," Carbohydrate Polymers, vol. 14, no. 2, pp. 115-130, 1990. 
[28] J. M. R. Patino, C. C. Sánchez, and Ma. R. R. Niño, "Implications of interfacial characteristics of food foaming agents in foam formulations," Advances in Colloid and Interface Science, vol. 140, no. 2, pp. 95-113, 2008.

[29] D. He, Y. Shi, F. Feng, and D. Zhan, "Study on gelation of chitosan and xanthan gum," Journal of Wuhan University, vol. 47 , no. 6 , pp. $717-720,2001$. 

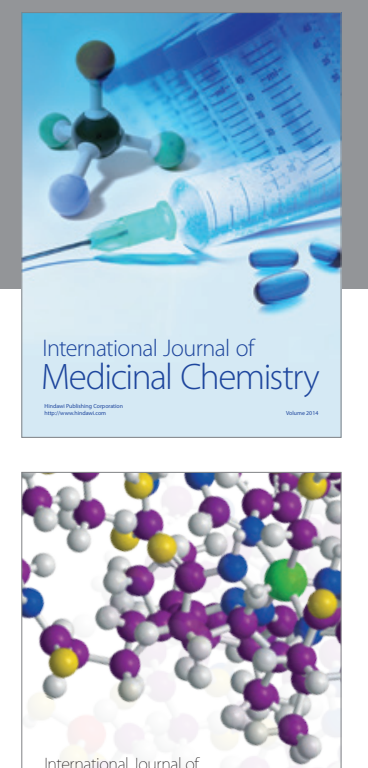

\section{Carbohydrate} Chemistry

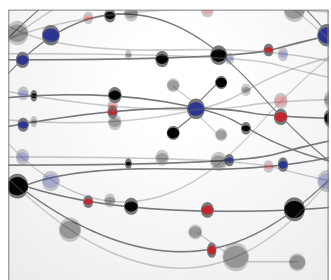

The Scientific World Journal
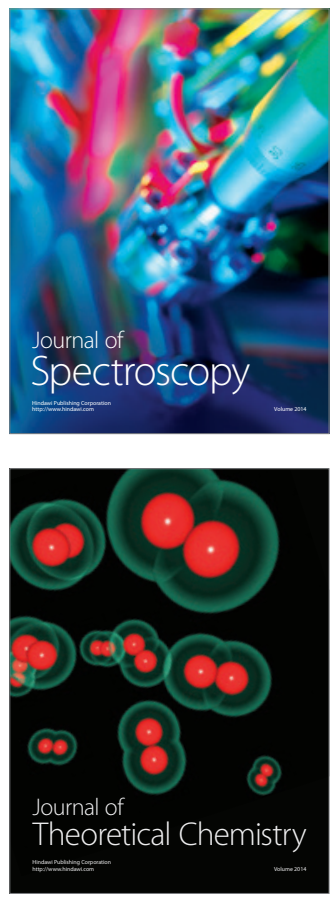
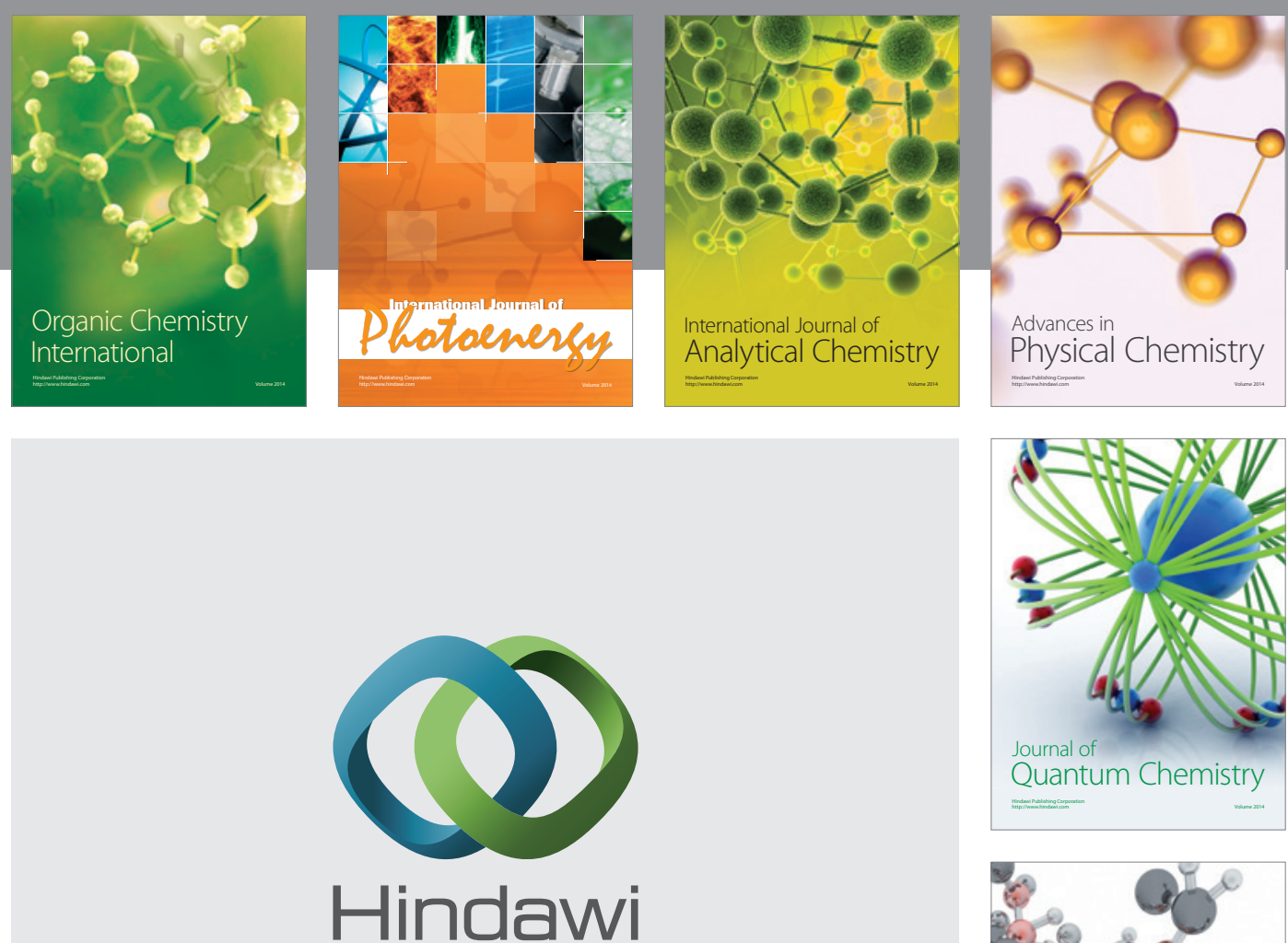

Submit your manuscripts at

http://www.hindawi.com

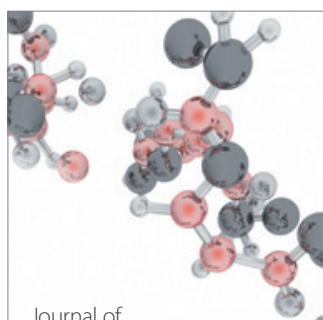

Analytical Methods

in Chemistry

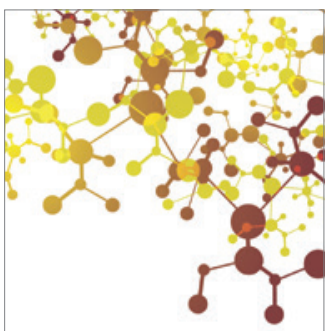

Journal of

Applied Chemistry

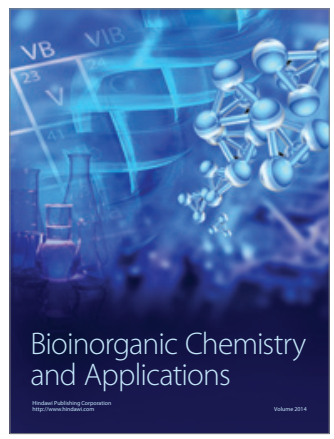

Inorganic Chemistry
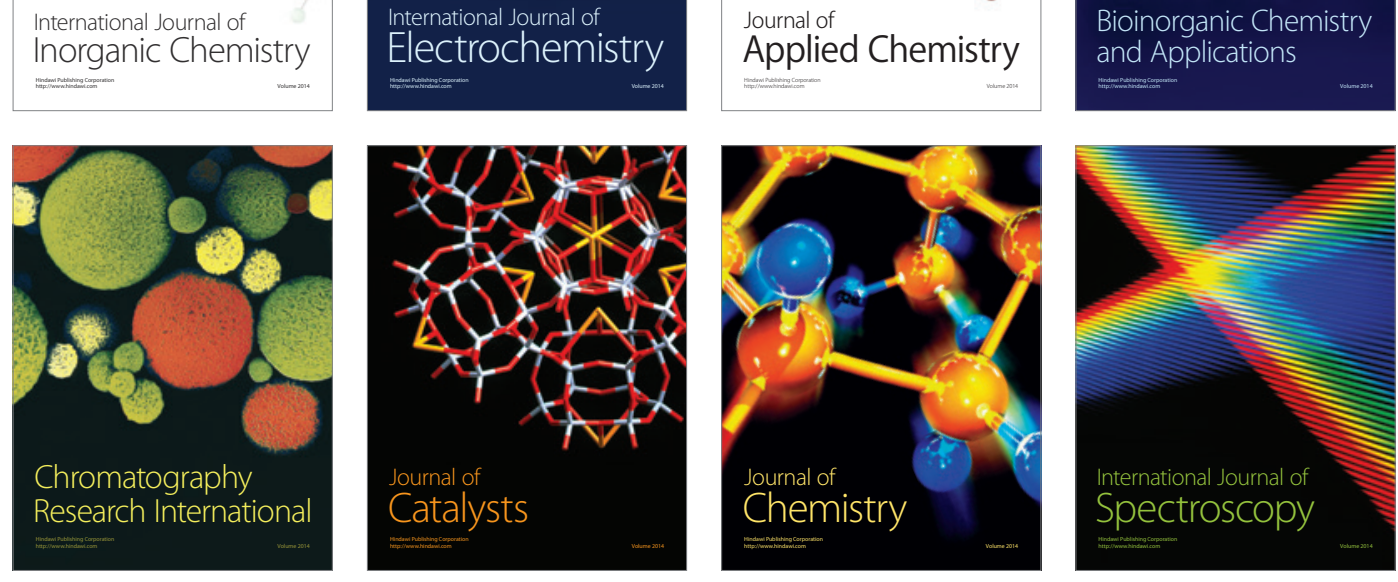